\title{
Motivation and Emotions of Gifted and Regular Students Performing a Creative Task
}

\author{
Detlef Urhahne* and Dagiadi Alcazar Ortiz
}

\author{
Psychology of Excellence in Business and Education, Department of Psychology, Ludwig-Maximilians-University, \\ Munich, Germany
}

\begin{abstract}
The study deals with the question whether gifted students differ from regular students when performing a creative task. A total of 140 students from a rural and an urban secondary school for gifted students in Germany took part in the investigation. The 58 students from gifted classes were similar with respect to age and gender distribution to the 82 students from regular classes. Students were tested on their motivation and emotions before they started to work on the creative task of either writing a poem or painting a picture. Most of the students, 129 out of 140, decided for picture painting. The gifted sixth and seventh graders showed a clearly higher creative achievement than regular sixth and seventh grade students. Gifted students were found to experience higher motivation for the creative task and had higher selfefficacy for creative achievements than average-ability students. No significant differences could be detected with respect to positive and negative affect. The study findings substantiate the main proposition of Renzulli's three-ring conception of giftedness that above-average abilities, creativity and task motivation are the defining factors of extraordinary talent.
\end{abstract}

Keywords: Gifted students, motivation, emotion, creativity.

\section{INTRODUCTION}

Creativity is a complex phenomenon [1] that prompted researchers to create varying definitions. In the core of these definitions is often the notion that creativity enables a person the production of novel and useful ideas [2]. The definition holds even true for artistic products when usefulness is interpreted as the ability of meeting certain task constraints. A wider definition of creativity by Franken, however, makes it easier to reconcile different creative achievements in divergent domains such as engineering, science, technology, humanities and arts. He defines creativity "as the tendency to generate or recognise ideas, alternatives, or possibilities that may be useful in solving problems, communicating with others, and entertaining ourselves and others" [3, p. 396]. In this definition, problem solving is on a par with aspects of communication and entertainment. While the former is typical for the hard sciences such as engineering, science and technology, the latter characterises creative processes in the soft sciences such as humanities, music, literature and the arts.

In this study, the focus is on the creativity of sixth and seventh grade students in poetry and arts. Creative achievements in these domains are often ascribed to extraordinary talent or giftedness [4]. Even though children of the ages 12 to 13 are not able to produce big creative performances in poetry and arts that can change the domain, they have the ability for little creative solutions by discovering novel ways in dealing with open-ended tasks. One question that specifically caught our interest was

*Address correspondence to this author at the Psychology of Excellence in Business and Education, Ludwig-Maximilians University, Martiusstrasse 4, D-80802 Munich, Germany; Tel: +49 (0) 892180-9791;E-mail: urhahne@lrz.uni-muenchen.de whether students of high IQ could produce better creative outcomes than students of average IQ. Therefore, students from gifted and regular classes were selected in order to investigate their creativity in self-chosen artistic tasks.

Creativity is often named in concert with motivation and affect [5-10]. Several researchers have emphasised the conducive role of intrinsic motivation for engaging in creative tasks [11-13]. Creative self-efficacy, the conviction of being able to produce creative outcomes, is another supporting factor for the generation of new and unconventional ideas [10]. Finally, positive mood states have been demonstrated to be a stronger predictor of creativity than neutral or negative mood states [8]. Another question we became interested in was whether gifted and regular students differ in their motivational-affective experiences during performing a creative task. As creativity, motivation and giftedness are in close connection to each other [7], it might be that students of gifted classes will show different motivation and emotions than students of regular classes.

\section{CREATIVITY AND GIFTEDNESS}

Creativity, the ability to make something unique und useful, is a much desired and respected talent and regarded as a vital component of giftedness [5, 14]. Multidimensional approaches of giftedness incorporate creativity as a moderatoring variable for bringing talent into outstanding performance [5], or as a dispositional factor that is necessary to produce expectional achievements in certain domains but is less required in other domains [15]. The threshold theory expresses a special relation between creativity and giftedness. The theory states that a moderate amount of intelligence is necessary to produce creative outcomes. Beyond the critical level of intelligence, the relationship to creativity is less close [16-18]. Empirical evidence for the threshold theory, however, is mixed, depending on the 
investigated ability groups and the varying assessment methods to measure intelligence and creativity [19]. Nevertheless, even if the threshold theory might not be conclusively proven, it can be definitely stated that creativity and intelligence are closely related to each other and medium correlations between these variables of .50 are the rule rather than the exception [19]. Taken into account the empirically supported relationship between creativity and giftedness, the conclusion can be drawn that gifted students would be more likely to produce high creative products than regular students if both groups will be asked to perform an artistic task.

\section{CREATIVITY, GIFTEDNESS AND MOTIVATION}

Creative behaviours are often said to be accompanied by high level of passion, persistence and devotion [20]. Creativity seems to be motivated by the enjoyment and satisfaction that a person perceives while acting on the creative task. This type of conducive motivation to creativity has been termed intrinsic. Amabile [21, p. 115] provides the following definition for it: "We define as intrinsic any motivation that arises from the individual's positive reaction to qualities of the task itself: this reaction can be experienced as interest, involvement, curiosity, satisfaction, or positive challenge". In contrast to intrinsic motivation stands extrinsic motivation, which is described by Amabile [21, p. 115] as following: "We define as extrinsic any motivation that arises from sources outside of the task itself; these sources include expected evaluation, contracted-for-reward, external directives, or any of several similar sources". In the first place, Amabile [22] assumed that any kind of extrinsic incentive given to participants for performing a task would be detrimental to creativity. Later on, this extreme position had to be revised as many studies have shown positive effects of rewards on different aspects of creative performance [20]. Only controlling extrinsic motivation has been found to be detrimental to creativity, whereas informational or enabling extrinsic motivation enhances the likelihood of high creative performances.

Creative self-efficacy is another form of motivation that can affect students' creative behaviours. In congruence to Bandura's self-efficacy construct [23], creative self-efficacy is defined as the belief of an individual in one's abilities to produce creative outcomes [24]. Beghetto [10] has shown that students of high creative self-efficacy take more often part in after-school activities such as playing in a band, doing drama or arts than students of low creative selfefficacy.

Since Terman in the 1950s compared the most successful and the least successful gifted participants of a longitudinal study in the midpoint of their careers, it is known that motivation is a decisive factor for the life success of gifted people [25]. Some more modern studies focused in detail on the motivation of gifted and regular students. In comparison to average-ability students, gifted students were found to have a higher academic self-concept, higher intrinsic motivation and perceived competence, higher self-efficacy for math and self-regulated learning, show more interest for school topics but do not differ with regard to mastery and performance goal orientation [26-28]. From this latter research can be derived that gifted students will differ in some motivational aspects from regular students when they are going to work on a creative task.

\section{CREATIVITY, GIFTEDNESS AND EMOTIONS}

Many studies have shown that positive affect helps to relate and integrate divergent material in a useful and reasonable way [8]. Without a doubt, positive affect promotes creativity [29]. The relation can be explained by the broaden-and-built theory of positive emotions [30]. Positive emotions like joy, happiness or interest broaden an individual's momentary thought-action repertoire. The positive emotions trigger novel and creative actions, which in turn help the individual to build up one's personal resources. These physical and psychological resources can be drawn on later when the individual is encountered with similar creative tasks.

There is also ample evidence that negative emotions like fear and anxiety hamper creativity [8]. These negative, activating moods with an avoidance tendency are detrimental for creative achievements, whereas positive, activating moods like enjoyment or happiness promote creative behaviours best.

Gifted children are often supposed to differ from regular education students in their social-emotional needs [31]. Excessive perfectionism striving, for example, might influence gifted students' experiences and might arouse stronger emotions in case of success or failure. Su, however, in a comparative study found no significant differences between gifted and average school children on their scores of emotional stability or their responses to positive and negative situations [32]. From this research, the conclusion can be drawn that gifted and ordinary students deal with emotions in a similar manner and are not prone to experience creative tasks differently.

\section{METHOD}

\section{Participants}

A total of 140 students from a rural and an urban secondary school for gifted students in Germany took part in the investigation. The rural school participated with a regular and a gifted sixth grade. The urban school was sending students from a regular and a gifted sixth grade and a regular and a gifted seventh grade. The total sample consisted of 78 boys and 62 girls who aged between 9 and 13 years $(M=11.22, S D=.80)$. The 58 gifted students $(57 \%$ male; $M=11.07$ years, $S D=.86$ ) were similar with respect to age and gender distribution to the 82 regular students (55\% male; $M=11.32$ years, $S D=.74$ ) of the sample.

\section{Materials}

Three measuring instruments were used to test students' motivation and emotions in the face of performing a creative task: the Questionnaire on Current Motivation (QCM) [33, $34]$, the PANAVA [35, 36], and the creativity self-efficacy scales [37, 38].

The QCM [33, 34] measures the current motivation of participants in experimental or real-life situations. The questionnaire is built on theoretical conceptions of achievement motivation and interest research. It comprises four factors, which the authors termed probability of success, 
challenge, interest, and anxiety. The first factor, probability of success, measures learner's belief to succeed in an upcoming task. This factor can be traced back to theoretical developments of Atkinson [39] or Wigfield and Eccles [40] who proposed expectancy-value models for the explanation of human motivation. The second factor, challenge, covers whether the participant interprets an upcoming task as an achievement-related topic. In this case, the achievement motive is stimulated and the learning situation gains importance [40]. The third factor, interest, measures to what extent the participant is attracted by the task. Interested learners experience more positive affect and are willing to invest more time and effort into tasks [41]. The fourth factor, anxiety, expresses the concerns of the participants to fail in the upcoming task. The factor anxiety represents the negative incentives of the task and is similar to the concept fear of failure of Atkinson's achievement motivation theory [39]. In the study, the items of the QCM were measured on a sevenpoint Likert scale.

The PANAVA by Schallberger [35] is an adaptation of the better-known PANAS scales by Watson et al. [36]. The theoretical framework of the PANAVA is grounded on two affective dimensions, typically labeled as arousal and pleasantness-unpleasantness. The term PANAVA itself represents the three factors of the questionnaire, which are called positive activation, negative activation, and valence. Positive activation describes the extent to which a participant feels energetic and highly motivated. Negative activation, in contrast, measures the person's aversive moods like distress and nervousness. Valence, the third factor, was added by Schallberger [35] to the PANAS scales [36] and reflects the aspect of pleasantness-unpleasantness. The ten items of the PANAVA are constructed as a semantic differential on which the testee has to decide between a positive and a negative pole (e.g., content-discontent) by making use of a seven-point Likert scale.

The creativity self-efficacy scales $[37,38]$ are developed in accordance with the theoretical concept of self-efficacy by Bandura [23]. He defined perceived self-efficacy as "beliefs in one's capabilities to organise and execute the courses of action required to produce given attainments" [23, p. 3]. Correspondingly, creativity self-efficacy represents the conviction to have the necessary skills and abilities in order to produce creative outcomes [24]. Hill et al. [38] distinguished between three aspects of creativity selfefficacy, which represent different aspects of the creativity self-efficacy construct. The first factor, creative self-efficacy, measures in correspondence to Beghetto [10] student's belief of being able to generate novel and useful ideas. The second factor, cognitive style, expresses the conviction that a person has the ability to handle and tolerate uncertainty in the creative process. The third factor, working style, stands for student's belief to deeply focus on issues related to creativity and problem solving. In the study, a five-point Likert scale ranging from "completely not true" to "completely true" was used to measure the different facets of creativity selfefficacy.

Table 1 summarises the different scales that were applied to assess students' current motivation and emotions. It can be seen that the reliability of the scales varies and in case of positive valence is relatively low. All other reliabilities are at least sufficient to calculate some meaningful comparisons between gifted and regular students.

Two creative tasks were offered to the students in order to measure their creativity. Students could decide between writing a poem and drawing a painting. Most of the students chose to create a painting $(n=129)$ instead of a poem $(n=$ 11). However, there were no differences between gifted and regular students to opt for one or the other opportunity $\left(\chi^{2}(1)\right.$ $=.99, p=.36)$. Ninety per cent of the regular students and 95 per cent of the gifted students decided to work on a painting. Experienced painters from the art academy in Munich as well as literature students helped to construct scales for rating the creativity of students' poems and paintings. After several rounds of discussion about possible items, ten items were selected to evaluate the creativity of the products: The picture / poem (a) is creative, (b) is original, (c) shows something new, (d) was created by using a special technique, (e) is unconventional, (f) is an extraordinary composition, (g) consists of unconventional forms, (h) fulfills the task appropriately, (i) has a certain meaning, and (j) represents a beautiful wish or dream. Students' creative achievements were evaluated on these items by using a five-point Likert scale. Due to time and financial constraints, two raters evaluated not all, but thirty selected creative products. The correlations between their ratings showed a considerable

Table 1. Number of Items, Sample Items and Reliabilities of the Scales

\begin{tabular}{|c|c|c|c|}
\hline Scale & \# of Items & Sample Item & Cronbach's Alpha \\
\hline \hline Probability of success & 4 & I think I match up to the difficulty of the task. & .69 \\
\hline Challenge & 4 & The task is a real challenge for me. & .54 \\
\hline Interest & 5 & I like those tasks. & .86 \\
\hline Anxiety & 5 & I feel under pressure to do well on this task. & .71 \\
\hline Positive activation & 4 & excited & .56 \\
\hline Negative activation & 4 & nervous & .43 \\
\hline Positive valence & 2 & content & .79 \\
\hline Creative self-efficacy & 5 & I have a lot of good ideas. & .56 \\
\hline Cognitive style & 5 & I can tolerate ambiguity. & .66 \\
\hline Working style & 5 & & \\
\hline
\end{tabular}


overlap, which signalises the objectivity and reliability of the judgment procedure. Two examples of students' creative drawings can be found in the Appendix.

Besides gender and age, students were asked about their attitudes of liking to write poems and paint pictures. Students used a five-point Likert scale to indicate their preferences for performing a creative task. Furthermore, students were asked about the last grades on their report cards in arts and German. The German grading system permits grades from 1 (best grade) to 6 (worst grade).

\section{Procedure}

The students were investigated in groups of school classes. The participation of the after-school activity was on voluntary basis. In a friendly introduction, students were acquainted with the purpose of the study. They were confirmed that all information would be kept confidential and that neither parents nor teachers would be informed about the study results. Afterwards, they were handed the questionnaire for measuring students' motivation and emotions. Students could fill in the four-page questionnaire without any difficulties in about 15 minutes. For the practical activity, they could choose to paint or write. Students were told that they should think of a dream, idea, or memory that was beautiful, pleasant, or made them happy in order to induce some positive affect for performing the creative task. The whole investigation could be finished within one school lesson.

\section{RESULTS}

Most of the students, 129 out of 140, decided for painting pictures instead of writing poems. The reason for the predominance of paintings becomes clear when the descriptive statistics in Table $\mathbf{2}$ are inspected: The undergraduate students have a marked preference for painting pictures instead of writing poems. A t-test for dependent samples underlines that painting a picture is clearly the more attractive task $(t(139)=11.45, p<.001, d=$ 1.19). The result is corroborated by the finding that students' grades in arts are much higher than in German $(t(137)=$ $5.40, p<.001, d=.58$ ). Furthermore, the descriptive results reveal that the students do not perceive the creativity task as terrifying as they are not anxious and feel a high probability of success. Some students perceive the creative task as interesting and challenging, while others hold completely opposite opinions (cf. Table 2). However, students' positive activation strongly outweighs students' negative activation $(t(139)=11.13, p<.001, d=.98)$. Most of the students experience high creativity self-efficacy, whereas students' real creative outcomes are not judged that highly (cf. Table 2).

In the center of the study is the question whether gifted students differ from regular students when performing a creative task. First of all, it can be seen from the t-tests for independent samples in Table $\mathbf{3}$ that gifted students hold similar preferences as regular students for writing poems and painting pictures. This goes along with the finding that gifted students made similar choices of creative tasks than regular students. Gifted students are having better grades in German but not in visual arts. Therefore, it wonders that the creative outcomes of the gifted students were much better rated than the creative outcomes of the regular students (cf. Table 3). This is not the only significant difference: Gifted students have a higher creative self-efficacy and rate higher in cognitive style and working style in comparison to regular students. Confronted with performing a creative task, gifted students showed elevated motivation and emotions. On both situation-specific measures, the QCM and the PANAVA, gifted students come off at least as well as regular students. However, the only significant difference emerges on the challenge dimension of the QCM. Gifted students perceive the upcoming creative task as more challenging than regular students (cf. Table 3 ).

Table 2. Descriptive Statistics

\begin{tabular}{|c|c|c|c|c|}
\hline Variable & $\boldsymbol{M}$ & $\boldsymbol{S D}$ & Min & Max \\
\hline \hline Writing poems & 2.51 & 1.23 & 1.00 & 5.00 \\
\hline Painting pictures & 3.93 & 1.15 & 1.00 & 5.00 \\
\hline Grade Arts & 2.04 & .78 & 1.00 & 4.00 \\
\hline Grade German & 2.52 & .86 & 1.00 & 5.00 \\
\hline Probability of success & 5.73 & 1.08 & 2.50 & 7.00 \\
\hline Challenge & 4.19 & 1.25 & 1.00 & 6.75 \\
\hline Interest & 4.64 & 1.60 & 1.20 & 7.00 \\
\hline Anxiety & 2.02 & 1.08 & 1.00 & 5.20 \\
\hline Positive activation & 4.58 & 1.11 & 1.00 & 7.00 \\
\hline Negative activation & 2.79 & 1.13 & 1.00 & 6.25 \\
\hline Positive valence & 5.29 & 1.22 & 1.00 & 7.00 \\
\hline Creative self-efficacy & 3.76 & .69 & 2.20 & 5.00 \\
\hline Cognitive style & 3.44 & .62 & 1.60 & 5.00 \\
\hline Working style & 3.80 & .65 & 1.80 & 5.00 \\
\hline Creative outcome & 2.92 & .87 & 1.00 & 5.00 \\
\hline
\end{tabular}

In order to come to know what mainly separates gifted students from regular students when performing a creative task, a stepwise logistic regression analysis on the variable "gifted / regular student" was executed. All variables of Table 3 were included that revealed a significant difference between gifted and regular students on the $\alpha$-level of .05. As recommended by Field [42], the forward likelihood ratio method was used to calculate the stepwise logistic regression analysis. The results of Table 4 reveal that German grades make a big difference between gifted and regular students as they first enter into the regression model. In the second step, the motivation variable challenge becomes significant. Perceiving the creative task as challenging is another big difference between gifted and regular students. The third step of the logistic regression analysis shows that creative performance is an indicator of giftedness. Gifted students are able to produce higher creative outcomes than regular students. The fourth step of the logistic regression analysis elucidates that gifted and regular students differ in cognitive style. Gifted students can tolerate uncertainty and ambiguity more easily than regular students. Creative self-efficacy and working style turned out to be insignificant predictors and were excluded from the regression model. The full 
Table 3. Comparison between Gifted and Regular Students

\begin{tabular}{|c|c|c|c|c|c|}
\hline \multirow{2}{*}{ Variable } & Gifted Students & Regular Students & \multirow{2}{*}{$t$} & \multirow{2}{*}{$p$} & \multirow{2}{*}{$d$} \\
\hline & $M(S D)$ & $M(S D)$ & & & \\
\hline Writing poems & $2.64(1.28)$ & $2.41(1.19)$ & 1.06 & .29 & .18 \\
\hline Painting pictures & $3.84(1.23)$ & $3.99(1.09)$ & -.72 & .47 & .12 \\
\hline Grade Arts & $2.16(.80)$ & $1.96(.77)$ & 1.45 & .15 & .25 \\
\hline Grade German & $2.23(.68)$ & $2.72(.90)$ & -3.52 & .001 & .60 \\
\hline Probability of success & $5.88(1.05)$ & $5.63(1.09)$ & 1.36 & .18 & .23 \\
\hline Challenge & $4.59(1.01)$ & $3.91(1.34)$ & 3.42 & .001 & .59 \\
\hline Interest & $4.92(1.59)$ & $4.45(1.59)$ & 1.73 & .09 & .30 \\
\hline Anxiety & $1.84(.97)$ & $2.15(1.14)$ & -1.71 & .09 & .29 \\
\hline Positive activation & $4.73(1.04)$ & $4.48(1.15)$ & 1.36 & .18 & .23 \\
\hline Negative activation & $2.60(1.16)$ & $2.92(1.09)$ & -1.65 & .10 & .28 \\
\hline Positive valence & $5.25(1.28)$ & $5.32(1.18)$ & -.35 & .73 & .06 \\
\hline Creative self-efficacy & $3.91(.65)$ & $3.65(.70)$ & 2.31 & .02 & .40 \\
\hline Cognitive style & $3.65(.61)$ & $3.30(.59)$ & 3.47 & .001 & .60 \\
\hline Working style & $4.00(.62)$ & $3.66(.63)$ & 3.24 & .001 & .56 \\
\hline Creative outcome & $3.17(.80)$ & $2.74(.89)$ & 2.94 & .01 & .50 \\
\hline
\end{tabular}

regression model is able to explain $29 \%$ of variance as indicated by Nagelkerke's $\mathrm{R}^{2}$.

\section{DISCUSSION}

The study focused on the motivational and affective differences between gifted and regular students when performing a creative task in literature or arts. The main results were that gifted sixth and seventh graders showed a clearly higher creative achievement than regular sixth and seventh grade students. Gifted students were found to experience higher motivation for the creative task and showed higher creativity self-efficacy than average-ability students. No significant differences could be found in positive and negative activation, i.e., gifted and regular students were reporting similar affects. Stepwise logistic regression analysis was used to unveil the major differences between student groups with respect to creativity issues. Gifted students showed not only higher academic abilities than regular students but perceived the creative task as more challenging, could more easily tolerate ambiguity and uncertainty, and ended up with a higher creative achievement.

The study sheds light to some uncovered aspects of creativity research. Most of the studies on creativity in the

Table 4. Stepwise Logistic Regression Analysis for the Variable "Gifted / Regular Student"

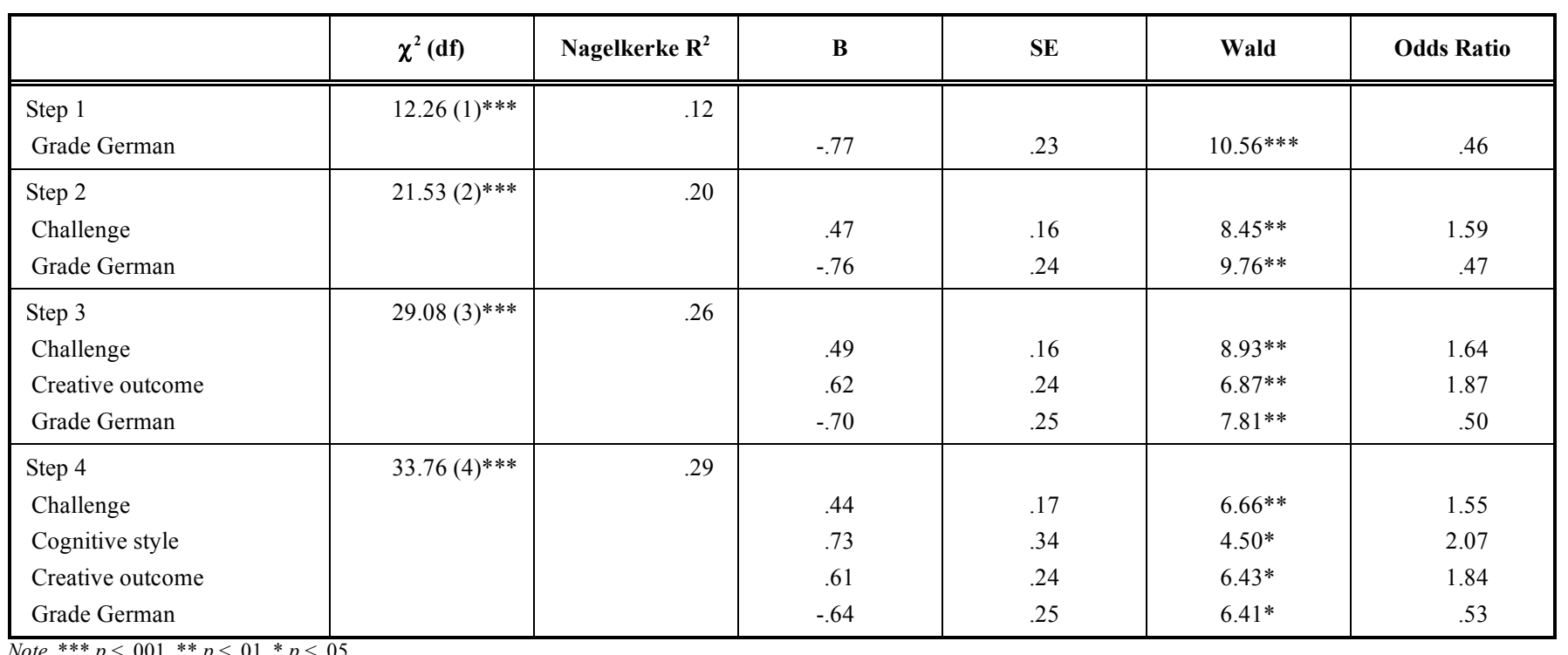


soft sciences such as literature or arts make use of a qualitative approach and deliver descriptive information about the significance of creative products [4]. In this study, the creative products were evaluated on rating scales in order to quantify the information and compare student groups of different ability levels. The results demonstrate the meaningfulness of the quantitative approach as gifted students were found to produce poems and drawings of higher creativity than regular students. The study findings are in line with cognitively oriented research on the relationship between giftedness and creativity [19]. Whereas the positive connection between intelligence and divergent problem solving is intuitively understandable, the link between intelligence and artistic achievement as measured in this study is less obvious. It can be speculated that the higher $\mathrm{g}$ factor [43] enables gifted students to create artifacts of better quality than regular students. Assumed that the specific abilities of gifted and regular students to work on artistic tasks are basically the same, the higher general abilities might turn the balance in favour of the gifted students. However, the raised argument can serve just as one explanation and further, more specific investigations have to show the validity of this line of reasoning.

A second remarkable finding of the study is the higher motivation of gifted students. Gifted students, in comparison to regular students, perceive the artistic task much more as a challenge and show a tendency of higher interest and less anxiety of the imminent creative situation. In addition, all measures of creativity self-efficacy, i.e. creative selfefficacy, working style and cognitive style, reveal a motivation advantage for the gifted students. The results cannot be explained by higher artistic competencies of the gifted students as their grades in the arts do not differ from the regular students. Rather, it is a question of general attitudes towards creative situations. Gifted students seem to interpret the artistic situation more in terms of an achievement situation where they can make use of their competencies. The research findings are supported by former motivation studies that found a large spectrum of motivation variables in which gifted students are superior to ordinary students [26-28].

The study findings also substantiate Renzulli's three-ring model of giftedness [7] that mentions above-average abilities, creativity and task motivation as the defining factors of extraordinary talent. The gifted sixth and seventh graders fulfil Renzulli's criteria for being a genius more completely than regular students. They differ from ordinary students with respect to aptitude, creative achievement, current motivation and creativity self-efficacy. All these criteria make up their giftedness as demonstrated by the concluding stepwise logistic regression analysis. In every domain of the Renzulli model arise important differences between gifted and regular students.

There are certain limitations of the study which should be taken up and corrected in future research. Creativity is difficult to measure [44], particularly in the soft sciences of literature and arts. The self-developed rating scale to assess creativity was not tested on its internal consistency and interrater reliability, which can be seen as a major shortcoming of the study. Even though the research results are conclusive and gifted students outperform regular students on the creativity measure, doubts about the findings should remain. What is urgently needed would be an objective, reliable and valid assessment tool for the evaluation of creative products in literature and arts. As long as such a tool is missing, quantitative research in this area should be regarded with some healthy scepticism.

Another concern about the study findings can be raised due to the limited reliability of some measures. Reduced reliability makes it harder to detect significant differences between treatment groups. Especially the reliabilities of the PANAVA scales to measure students' emotions were relatively low. Therefore, it might be that affect differences between gifted and regular students could not be uncovered. Future research on students' emotions would be better off when a more reliable measuring instrument could be applied.

\section{CONCLUSIONS}

All in all, the study has given insight into the motivation and moods of gifted and regular students during creative processes. It became obvious that gifted students do not differ in one but many aspects from their same-aged peers. Higher cognitive and motivational functioning and better creative performance seem to justify the separation of gifted and regular students by dividing them into different school classes. In more homogenous groups, gifted students can make faster progress in learning and can encourage each other to do better. In more heterogeneous groups, however, regular students can profit and learn from the extraordinary abilities of the gifted students. Here, the opportunity is missed to compensate for the self-regulatory and creative underperformances of regular students.

If one of the students of the study really becomes a creative artist in the future cannot be foreseen. Besides some exceptional talent, some other conditions have to be fulfilled. Such a person should feel challenged and interested by creative tasks, should predominantly experience positive moods when working on the tasks and show high levels of creative self-efficacy to deliver extraordinary performances. Therefore, it is necessary to value not only the creative product but also the creative person behind it with all its cognitive, motivational and emotional abilities.

\section{ACKNOWLEDGEMENT}

None declared.

\section{CONFLICT OF INTEREST}

None declared.

\section{APPENDIX}

Two Pictures of Highly Creative Achievements. 

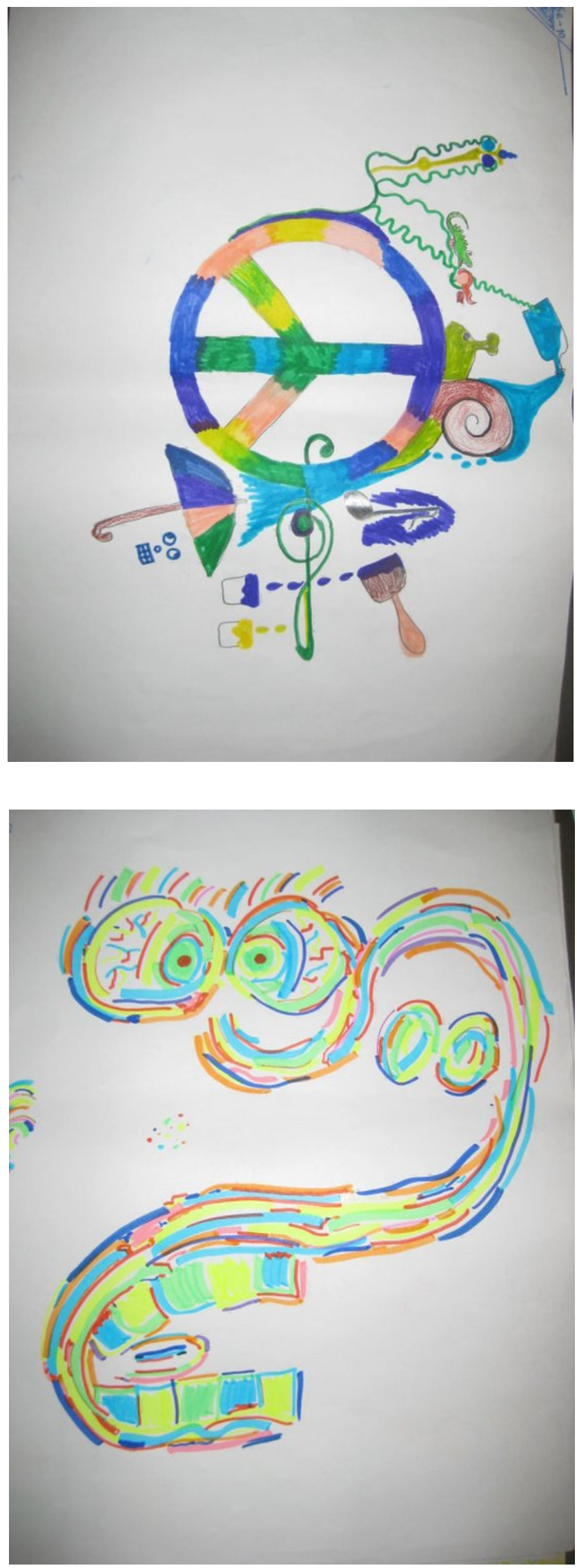

\section{REFERENCES}

[1] Matuga J. Situated creative activity: The drawings and private speech of young children. Creat Res J. 2004; 16: 267-81.

[2] Runco MA. Creativity. Ann Rev Psychol 2004; 55: 657-87.

[3] Franken RE. Human motivation. Pacific Grove, CA: Brooks/Cole 1994.

[4] Winner E, Martino G. Giftedness in non-academic domains: The case of visual arts and music. In: Heller KA, Mönks FJ, Sternberg RJ, Subotnik RF, Eds. International handbook on giftedness and talent. Amsterdam: Elsevier 2000; pp. 95-110.

[5] Renzulli JS. What makes giftedness? Reexamining a definition. Phi Delta Kappan. 1978; 60(3): 180-184, 261.

[6] Amabile TM. The social psychology of creativity: A componential conceptualization. J Pers Soc Psychol 1983; 45: 357-76.

[7] Renzulli JS. The three-ring conception of giftedness: A developmental model for promoting creative productivity. In: Sternberg RJ, Davidson JE, Eds. Conceptions of giftedness. Cambridge, UK: Cambridge University Press 2005; pp. 246-79.

[8] Baas M, De Dreu C, Nijstad B. A meta-analysis of 25 years of mood-creativity research: Hedonic tone, activation, or regulatory focus? Psychol Bull 2008; 134: 779-806.

[9] Schack GD. Self-efficacy as a mediator in the creative productivity of gifted children. J Educ Gifted 1989; 12: 231-49.

[10] Beghetto RA. Creative self-efficacy: Correlates in middle and secondary students. Creat Res J 2006; 18: 447-57.

[11] Sternberg RJ, Lubart TI. An investment theory of creativity and its development. Hum Dev 1991; 34: 1-32.

[12] Amabile TM. Motivation and creativity: Effects of motivational orientation on creative writing. J Pers Soc Psychol 1985; 48: 393-9.

[13] Csikszentmihalyi M. Motivation and creativity: Towards a synthesis of structural and energistic approaches to cognition. New Ideas Psychol 1988; 6: 159-76.

[14] Albert RS, Runco MA. The achievement of eminence: A model based on a longitudinal study of exceptionally gifted boys and their families. In: Sternberg RJ, Davidson JE, Eds. Conceptions of giftedness. New York: Cambridge University Press 1986; pp. 33260 .

[15] Gagné F. Understanding the complex choreography of talent development through DMGT-based analysis. In: Heller KA, Mönks FJ, Sternberg RJ, Subotnik RF, Eds. International handbook of giftedness and talent. Amsterdam: Elsevier 2000; pp. 67-79.

[16] Barron F. Creativity and psychological health. Princeton, NY: Van Nostrand 1963.

[17] Getzels JW, Jackson PW. Creativity and intelligence: Explorations with gifted students. New York: Wiley 1962.

[18] Runco MA, Albert RS. The threshold theory regarding creativity and intelligence: An empirical test with gifted and nongifted children. Creat Child Adult Q 1986; 11:212-8.

[19] Preckel F, Holling H, Wiese M. Relationship of intelligence and creativity in gifted and non-gifted students: An investigation of threshold theory. Pers Individ Dif 2006; 40: 159-70.

[20] Collins MA, Amabile TM. Motivation and creativity. In: Sternberg RJ, Ed. Handbook of creativity. New York: Cambridge University Press 1999; pp. 297-312.

[21] Amabile TM. Creativity in context. Boulder, CO: Westview 1996.

[22] Amabile TM. The social psychology of creativity. New York: Springer 1983.

[23] Bandura A. Self-efficacy. The exercise of control. New York: W. H. Freeman 1997.

[24] Tierney P, Farmer SM. Creative self-efficacy: Its potential antecedents and relationship to creative performance. Acad Manage J 2002; 45: 1137-48.

[25] Terman L. The discovery and encouragement of exceptional talent. Am Psychol 1954; 9: 221-30.

[26] Preckel F, Goetz T, Pekrun R, Kleine M. Gender differences in gifted and average-ability students. Comparing girls' and boys' achievement, self-concept, interest, and motivation in mathematics. Gifted Child Q 2008; 52: 146-59.

[27] Pajares F. Self-efficacy beliefs and mathematical problem-solving of gifted students. Contemp Educ Psychol 1996; 21: 325-44.

[28] Vallerand RJ, Gagné F, Senécal C, Pelletier LG. A comparison of the school intrinsic motivation and perceived competence of gifted and regular students. Gifted Child Q 1994; 38: 172-75.

[29] Isen AM, Daubman KA, Nowicki GP. Positive affect facilitates creative problem solving. J Pers Soc Psychol 1987; 52: 1122-31. 
[30] Fredrickson BL. The role of positive emotions in positive psychology: The broaden-and-built theory of positive emotions. Am Psychol 2001; 56: 218-26.

[31] Coleman LJ, Cross TL. Social-emotional development and the personal experience of giftedness. In: Heller KA, Mönks FJ, Sternberg RJ, Subotnik RF, Eds. International handbook of giftedness and talent. Amsterdam: Elsevier 2000; pp. 203-12.

[32] Su C-W. A study on the development of basic emotions of gifted children and adolescents. Bull Educ Psychol 1982; 15: 67-84.

[33] Vollmeyer R, Rheinberg F. Motivational effects on self-regulated learning with different tasks. Educ Psychol Rev 2006; 18: 239-253.

[34] Rheinberg F, Vollmeyer R, Burns BD. FAM: Ein Fragebogen zur Erfassung aktueller Motivation in Lern- und Leistungssituationen [QCM: A questionnaire to assess current motivation in learning situations]. Diagnostica 2001; 47: 57-66.

[35] Schallberger U. Qualität des Erlebens in Arbeit und Freizeit: Eine Zwischenbilanz [Quality of experience in work and leisure: An interim result]. Berichte aus der Abteilung Angewandte Psychologie, $\mathrm{Nr}$ 31. Zürich: Psychologisches Institut der Universität Zürich 2000.
[36] Watson D, Clark LA, Tellegen A. Development and validation of brief measures of positive and negative affect: The PANAS scales. J Pers Soc Psychol 1988; 54: 1063-70.

[37] Tan AG, Ho V, Yong LC. Singapore high school students' creativity efficacy. New Horizons in Education 2007; 55: 96-106.

[38] Hill A, Tan AG, Kikuchi A. International high school students' perceived creativity self-efficacy. Korean J Think Prob Solv 2008; 18: 105-15.

[39] Atkinson JW. Motivational determinants of risk-taking behavior. Psychol Rev 1957; 64: 359-72.

[40] Wigfield A, Eccles JS. Expectancy-value theory of achievement motivation. Contemp Educ Psychol 2000; 25: 68-81.

[41] Krapp A, Hidi S, Renninger KA. Interest, learning and development. In: Renninger KA, Hidi S, Krapp A, Eds. The role of interest in learning and development. Hillsdale, NJ: Erlbaum 1992; pp. 3-25.

[42] Field A. Discovering statistics using SPSS. London: Sage 2009.

[43] Jensen AG. The g factor: The science of mental ability. Westport, CT: Praeger 1998.

[44] Treffinger DJ. Myth 5: Creativity is too difficult too measure. Gifted Child Q 2009; 53: 245-7.

(C) Urhahne and Alcazar Ortiz; Licensee Bentham Open.

This is an open access article licensed under the terms of the Creative Commons Attribution Non-Commercial License (http://creativecommons.org/licenses/by-nc/ 3.0/) which permits unrestricted, non-commercial use, distribution and reproduction in any medium, provided the work is properly cited. 